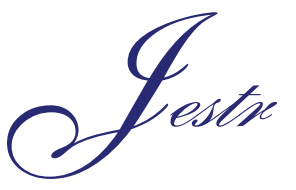

\title{
Performance of Fly ash Based Geopolymer Mortars in Sulphate Solution
}

\author{
S. Thokchom ${ }^{1, *}$, P. Ghosh ${ }^{2}$ and S. Ghosh ${ }^{1}$ \\ ${ }^{\prime}$ Department of Civil Engineering, Jadavpur University, Kolkata-32, India. \\ ${ }^{2}$ Department of Construction Engineering, Jadavpur University, Kolkata-32, India.
}

Received 19 August 2009; Revised 2 December 2009; Accepted 24 February 2010

\begin{abstract}
An experimental investigation was conducted to study the performance of fly ash based geopolymer mortar specimens in Magnesium Sulphate solution. Specimens were manufactured from low calcium fly ash by activation with a mixture of Sodium Hydroxide and Sodium Silicate solution and cured thermally. $10 \%$ by weight Magnesium Sulphate solution was used to soak the specimen up to 24 weeks. Performance of the specimens was evaluated in terms of visual appearance, variation of $\mathrm{pH}$ of solution, change in weight, and change in compressive strength over the exposure period. White deposits occurred on the surface of specimen which was initially soft but later converted to hard crystals. pH of solution increased noticeably during the initial weeks which indicate migration of alkalis from mortar specimens. At the end of 24 weeks samples experienced very little weight gain and recorded a loss of compressive strength by up to $56 \%$.
\end{abstract}

Keywords: Fly ash, geopolymer, durability, pH value, weight change, compressive strength.

\section{Introduction}

Sulphate attack on cement concrete is reported to be a complex process [1]. Mechanism of attack and the type of distress caused by different sulphate solutions containing $\mathrm{Ca}, \mathrm{Na}, \mathrm{Mg}$ and $\mathrm{Fe}$ as the cations proceeds differently [2]. It has been recognized that ettringite and gypsum are the primary products of the chemical reaction between sulphate bearing solution and cement hydration products. Ettringite are reported to cause expansion leading to failure of concrete specimens[3], [4], [5]. Bonen and Cohen [6] investigated the response of Portland cement pastes on magnesium sulphate and suggested that the attack by magnesium ions primarily leads to formation of a layer of brucite on the exposed surfaces.

Geopolymers are a class of new binder generally manufactured by activating an aluminosilicate source material in a highly alkaline medium. Davidovits [7] reported that geopolymers possess high early strength, better durability and has no dangerous alkali-aggregate reaction. So far investigations in geopolymers mostly deal with the manufacturing processes and effects of synthesizing parameters on physical and mechanical properties. Very few studies had been carried out with regard to durability of geopolymer materials. Geopolymers manufactured from fly ash have shown excellent performance when exposed to different acids with varying concentrations and exposure durations. [7] - [11].

*E-mail address: thok_s@rediffmail.com

ISSN: 1791-2377 C 2010 Kavala Institute of Technology. All rights reserved.
Wallah and Rangan[12] reported that geopolymer concrete specimens exhibit extremely small changes in length and also shows very little increase in mass after one year of exposure in sulphate solution. In another study by Bakharev [13] the author used various concentrations of sulphate solution to immerse the geopolymer materials prepared using different types of activating solutions.

The objective of present experimental program was to evaluate the performance of fly ash based geopolymer mortar specimens in Magnesium sulphate solution. The geopolymer mortars manufactured with varying contents of alkali were immersed in Magnesium sulphate solution and its performance was evaluated on the basis of appearance, changes in weight, $\mathrm{pH}$ and compressive strength at regular intervals over the exposure duration.

\section{Experimental}

\section{a. Materials}

Low calcium Class F fly ash used in the present experimental program was obtained from Kolaghat Thermal Power Plant near Kolkata, India. It had a chemical composition as in Table 1. About $75 \%$ of particles were finer than 45 micron and Blaine's specific surface was $380 \mathrm{~m}^{2} / \mathrm{kg}$. Fine sand was local river sand having specific gravity of 2.5 and fineness modulus of 2.65. Laboratory grade Sodium hydroxide in pellet form (98 percent purity) and 
Sodium Silicate solution $\left(\mathrm{Na}_{2} \mathrm{O}=8 \%, \mathrm{SiO}_{2}=26.5 \%\right.$ and $65.5 \%$ water) with silicate modulus $\sim 3.3$ and a bulk density of 1410 $\mathrm{kg} / \mathrm{m}^{3}$ was supplied by Loba Chemie Ltd. The alkaline activating solution was a mixture of Sodium hydroxide and Sodium silicate solution having $\mathrm{Na}_{2} \mathrm{O}$ in the mix as $5 \%$ to $8 \%$ of fly ash. Water to fly ash ratio was maintained at 0.33 .

Table 1. Chemical composition of Fly ash

\begin{tabular}{|c|c|c|}
\hline $\begin{array}{c}\text { Chemical } \\
\text { composition }\end{array} \mathrm{SiO}_{2} \mathrm{Al}_{2} \mathrm{O}$ & $\mathrm{Fe}_{2} \mathrm{O}_{3} \mathrm{TiO}_{2} \mathrm{CaO} \mathrm{MgO} \mathrm{K}_{2} \mathrm{O} \mathrm{Na} \mathrm{N}_{2} \mathrm{O}$ & $\mathrm{SO}_{3} \mathrm{P}_{2} \mathrm{O}_{5} \mathrm{LOI}^{*}$ \\
\hline Percentage 56.0129 .8 & $\begin{array}{llllll}3.58 & 1.75 & 2.36 & 0.30 & 0.73 & 0.61\end{array}$ & Nil $0.44 \quad 0.40$ \\
\hline
\end{tabular}

*Loss on ignition

\section{b. Specimen preparation}

The geopolymer mortar samples were prepared using equal proportions of fly ash and sand. The mixing procedure and curing regime adopted was after Thakur and Ghosh [14]. Fly ash was first mixed with the activator solution in a Hobart mixer for 5 minutes. The mix exhibited a thick sticky nature with good workability. Sand was then gradually introduced and further mixed for another 5 minutes. The mix was then transferred into $50 \mathrm{~mm}$ cube moulds and vibrated for 2 minutes. Specimens were cured along with the moulds in an oven for a period of 48 hours at $85^{\circ} \mathrm{C}$ and allowed to cool inside the oven before being removed to room temperature. The details of the samples used in the present study are given in the Table 2.The compressive strength determined at 28 days was found to be $22 \mathrm{MPa}, 37 \mathrm{MPa}$ and $40 \mathrm{MPa}$ for GM1, GM2 and GM3 respectively.

Table 2. Details of geopolymer mortar specimens

\begin{tabular}{ccccc}
\hline Sample ID & Activator & $\begin{array}{c}\mathrm{Na}_{2} \mathbf{O}, \\
\text { percent }\end{array}$ & $\begin{array}{c}\text { Fly ash : } \\
\text { sand }\end{array}$ & $\begin{array}{c}\text { Curing temp \& } \\
\text { Duration }\end{array}$ \\
\hline GM1 & $\begin{array}{c}\text { Sodium } \\
\text { hydroxide } \\
\text { GM2 }\end{array}$ & $5 \%$ & 1 & $85^{\circ} \mathrm{C} \& 48 \mathrm{hrs}$ \\
GM3 & silicate & $8 \%$ & 1 & $85^{\circ} \mathrm{C} \& 48 \mathrm{hrs}$ \\
\hline
\end{tabular}

\section{c. Test Procedure}

To study the performance of geopolymer mortar samples in sulphate environment, specimens were exposed in $10 \%$ solution of Magnesium Sulphate after 28 days from manufacture. The duration of exposure was 24 weeks and specimens were kept fully immersed in the sulphate solution having total volume as four times the volume of specimens immersed. The effects of magnesium sulphate on the geopolymer mortar specimen were constantly monitored through visual inspection, measurement of $\mathrm{pH}$ values, weight changes and strength tests at regular intervals during the exposure period.

Samples for weight change measurements were initially primed in water for 3 days and its weight in saturated surface dry condition was taken as initial weight. Change in weight was found out by the following equation.

Change in weight $(\%)=[(\mathbf{B}-\mathbf{A}) / \mathbf{A}] \times 100$

Where $\mathbf{A}=$ Initial weight of water primed specimen $\mathbf{B}=$ Weight of specimen after exposure

Residual compressive strength was calculated based on the following formula.

Residual compressive strength $(\%)=[\mathrm{D} / \mathrm{C}] \times 100$

Where $\mathbf{C}=$ Initial compressive strength at the age of 28 days $\mathbf{D}=$ Compressive strength after exposure

\section{Results and Discussion}

\section{a. Visual Appearance}

Geopolymer mortar specimens manufactured by activation of low calcium fly ash with an activating mixture of sodium hydroxide and sodium silicate solution did not show any change in shape and remained structurally intact without visible cracks. Specimen surfaces received white deposits throughout the duration of exposure. These deposits were soft and powdery during early stage of exposure but it became harder with time. It was observed that specimen containing lesser $\mathrm{Na}_{2} \mathrm{O}$ had the minimum white deposits. GM1 specimen containing only $5 \% \mathrm{Na}_{2} \mathrm{O}$ showed least deposits, on the other hand maximum deposit occurred in GM3 mortar specimen manufactured with $8 \% \mathrm{Na}_{2} \mathrm{O}$. Through the Optical microscope, flaky and elongated white deposits could be seen on the surfaces initially up to 12 weeks which at later stages were converted to hard and slightly rounded shapes. Few needle like formations were observed in the surface of specimens and a typical image of such structural formation is shown in Fig. 1 while Fig. 2 and Fig. 3 show the photographs of specimens after 3 weeks exposure and 24 weeks exposure respectively.

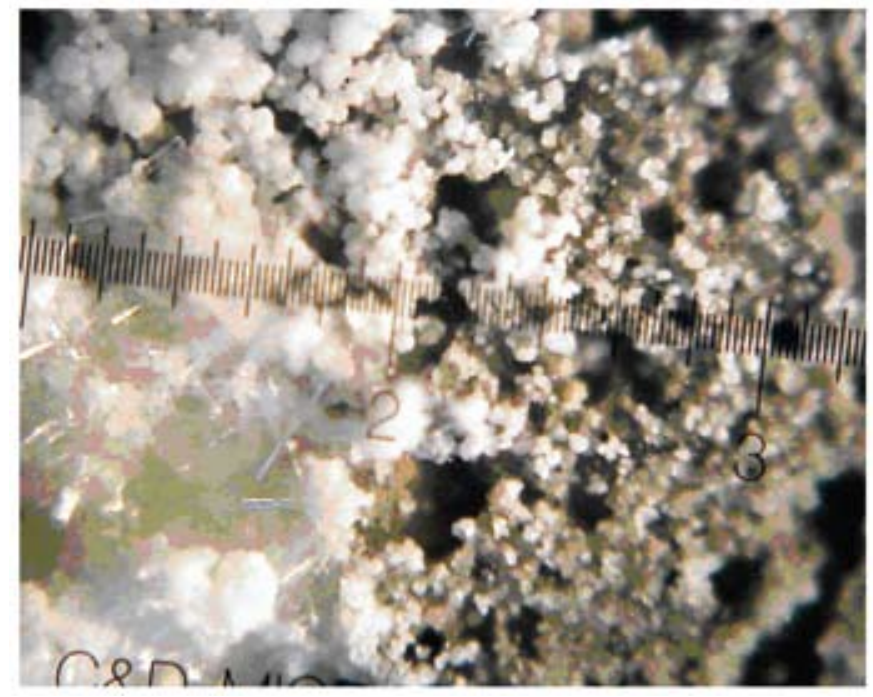

Figure 1. Needle like structures observed on the surface of specimen after 6 weeks exposure. 


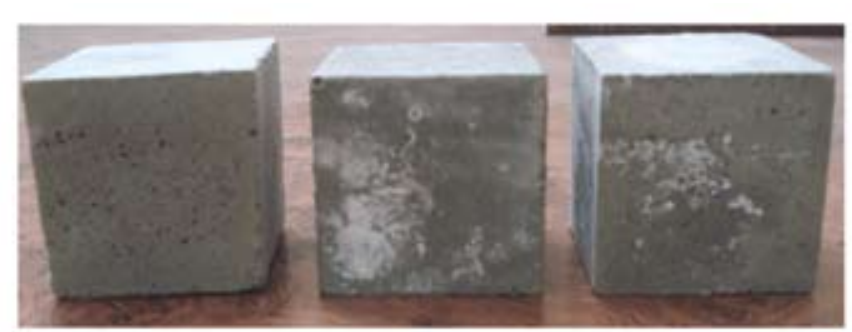

Figure 2. Geopolymer mortar specimens after 3 weeks exposure.

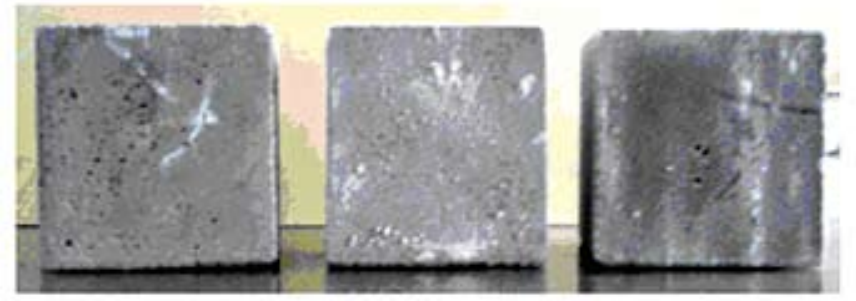

Figure 3. Geopolymer mortar specimens after 24 weeks exposure.

\section{b. pH of solution}

The variation in $\mathrm{pH}$ of the solutions containing the three different series of geopolymer mortar specimens GM1, GM2 and GM3 is shown in Fig. 4. The initial value of $\mathrm{pH}$ for $10 \%$ Magnesium sulfate solution prior to immersion of specimens was 7.92. After 18 weeks exposure $\mathrm{pH}$ increased considerably to about 9 in the solution containing GM3 specimen. The increase in $\mathrm{pH}$ was rapid during first three weeks and thereafter it was not appreciable. Though $\mathrm{pH}$ of all the solutions containing specimens with varying $\mathrm{Na}_{2} \mathrm{O}$ content showed an increase, maximum increase occurred in solution with GM3 specimen which had $8 \% \mathrm{Na}_{2} \mathrm{O}$. Specimens of GM1 and GM2 which were manufactured with lesser $\% \mathrm{Na}_{2} \mathrm{O}$ recorded lower $\mathrm{pH}$ values at the end of 18 weeks in Magnesium sulfate solution. The increase in $\mathrm{pH}$ may be attributed to migration of alkalis from specimen into the solution as reported by Bakharev [13]. Rate of migration of alkali appears to be higher within the initial weeks as indicated by the rapid rise in $\mathrm{pH}$ value at 3 weeks. Continuous exposure beyond 3 weeks did not result in notable increase which suggests that further migration of alkali from the specimen has diminished or rather stopped.

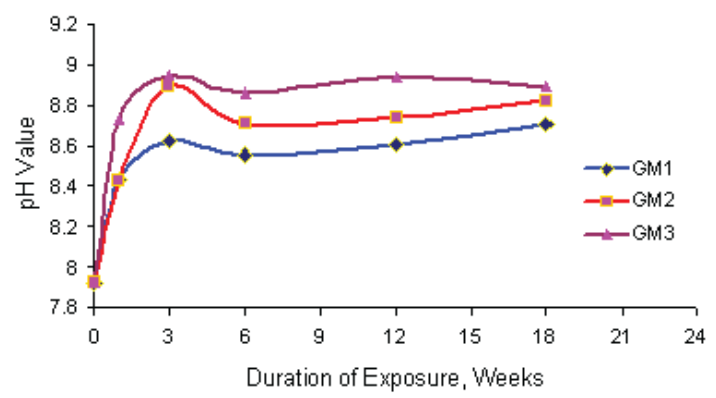

Figure 4. Variation of $\mathrm{pH}$ of exposure solution.

\section{c. Change in Weight}

The weight changes of geopolymer mortar specimens in Magnesium Sulphate solution are presented in Fig. 5. All the specimens recorded increase in weight over the duration of exposure. The pattern of weight gain is almost similar in the three different series of specimens. Maximum increase in weight was observed in GM1 specimen $\left(5 \% \mathrm{Na}_{2} \mathrm{O}\right)$ and least gain in weight occurred in GM3 specimen $\left(8 \% \mathrm{Na}_{2} \mathrm{O}\right)$. Till up to 6 weeks of exposure, there was rapid gain in weight. Thereafter increase of weight was gradual and after 18 weeks, a decreasing trend was observed for all the specimens. The weight gain across the specimens was in the range of $0.41 \%$ to $1.98 \%$ which is negligibly small. The increase in weight might be due to white deposits within the surface pores. These deposits were flaky or needle like during the early stages of exposure. Rendell and Jauberthie [15] observed such deposits on cement mortar specimens in sulphate environments which were confirmed as gypsum. On the basis of change in weight of specimens in sulfate solution, GM3 mortars manufactured by activation with highest alkali content performed better than those prepared with lesser alkali.

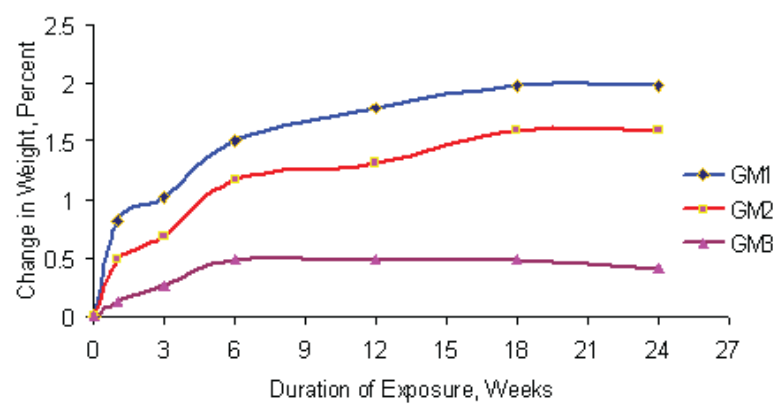

Figure 5. Changes in Weight of specimens.

\section{d. Residual compressive strength}

Fig. 6 represents the variation of residual compressive strength with time for the geopolymer mortar specimens in 10\% Magnesium Sulphate solution. During compressive strength test, specimens produced a continuous cracking sound which might be due to crushing of deposited crystals within the pores. Unlike in normal specimen, geopolymer mortar specimens exposed to sulphate solution threw out small pieces when crushed under the compression testing machine. After 24 weeks of exposure, all the specimens exhibited decrease in residual compressive strength though fluctuations in strength were recorded in between. GM2 and GM3 specimens showed greater fluctuations in strength than GM1 specimen which had least $\mathrm{Na}_{2} \mathrm{O}$ content. Loss of strength could be attributed to occurrence of micro cracks due to formation of gypsum and ettringite in the surface pores. The residual compres-

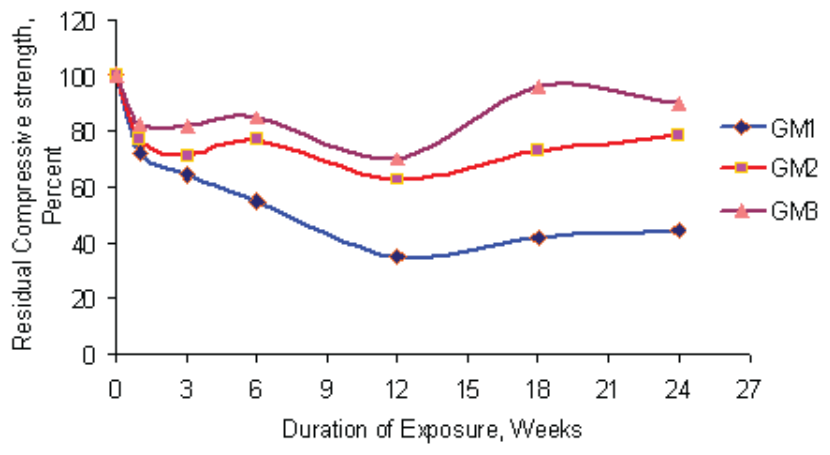

Figure 6. Residual compressive strength of specimens. 
sive strength was $44.13 \%, 78.56 \%$ and $89.7 \%$ for GM1, GM2 and GM3 specimens respectively. The performance in terms of greater strength retention was best in GM3 mortars which contain $\mathrm{Na}_{2} \mathrm{O}$ more than the other two geopolymer mortars GM1 and GM2.

\section{e. Scanning electron microscopy (SEM) and EDX}

Scanning electron microscopy (SEM) was performed on samples removed from the surface of unexposed specimen as well as from those exposed in Magnesium sulphate solution. In addition, EDX spectrum was obtained for the samples at selected spots. Fig. 7 present the SEM micrographs and EDX spectrum for indicated spots of GM2 specimen at various stages of exposure duration. Development of gel-like phases could be seen after exposure to magnesium sulphate solution. These formations appeared to increase with duration of exposure. At the end of 24 weeks in $10 \%$ Magnesium sulphate solution, the geopolymer specimen showed very dense microstructure due to formation of light coloured gel-like phases. EDX spectrum of spot-A in the unexposed GM2 specimen shows presence of aluminium $(\mathrm{Al})$, silica $(\mathrm{Si})$, iron $(\mathrm{Fe})$, calcium $(\mathrm{Ca})$, potassium $(\mathrm{K})$, oxygen $(\mathrm{O})$ and sodium $(\mathrm{Na})$. These elements were also present in the source fly ash. However, another EDX spectrum at spot B in the specimen after 6 weeks of exposure indicates presence of magnesium $(\mathrm{Mg})$ and sulphur(S) in the surface region. Bakharev [13] reported diffusion of magnesium and sulphur into the surface of specimens from the exposure solution. At the same time migration of calcium from within the mortar matrix to the surface area occurred. Notable increase in the $\mathrm{pH}$ of solution in all the three series of geopolymer mortar specimens indicates migration of alkalis from the specimen into the solution. Formation of gypsum $\left(\mathrm{CaSO}_{4} \cdot 2 \mathrm{H}_{2} \mathrm{O}\right)$ and ettringite $\left[\mathrm{Ca}_{6} \mathrm{Al}_{2}\left(\mathrm{SO}_{4}\right)_{3}(\mathrm{OH})_{12} \cdot 26 \mathrm{H}_{2} \mathrm{O}\right]$ could be possible as EDX spectrum of spot-D in the GM3 specimen reveals traces of constituent elements. Gypsum and ettringite are known to cause expansion in cement concrete when exposed in sulphate solution[3-6].In SEM micrographs of few samples, localized cracks were noticed which should be attributed to formation of ettringite. Due to these cracks, decrease in compressive strength occurred. In Fig.8, SEM images and EDX spectra at spot E and F for specimen GM1 and GM3 after 12 weeks exposure shows calcium and sulphur along with oxygen as main constituents other than magnesium and silicon which indicate possible formation of gypsum.
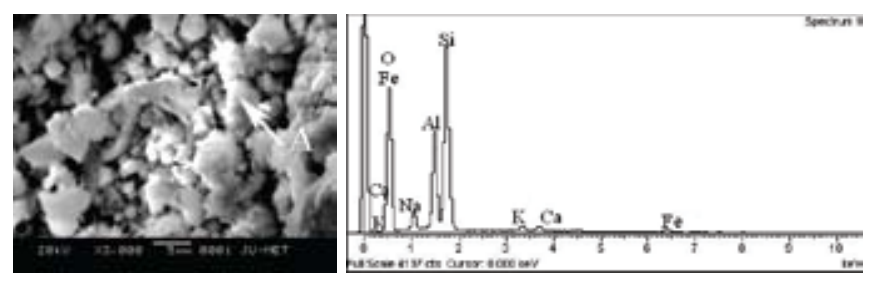

A-Unexposed specimen
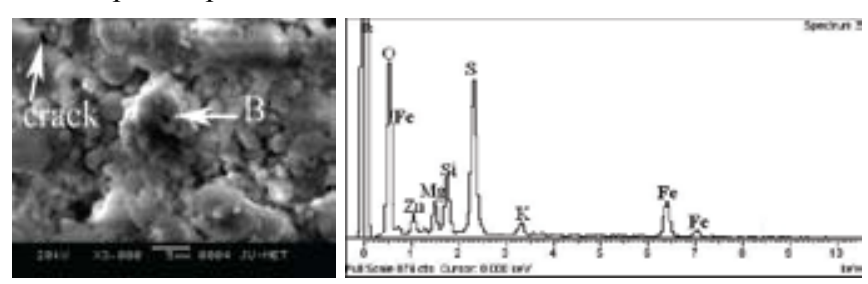

B- After 6 week exposure
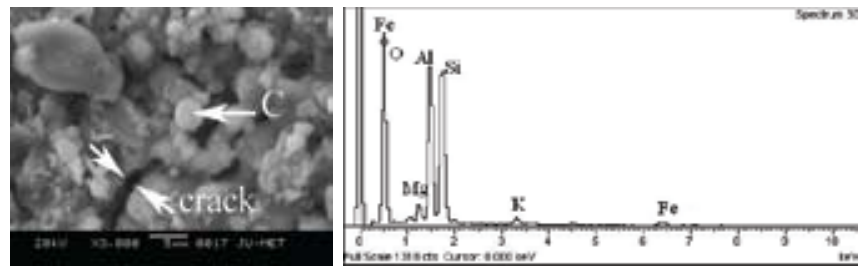

C- After 12 week exposure
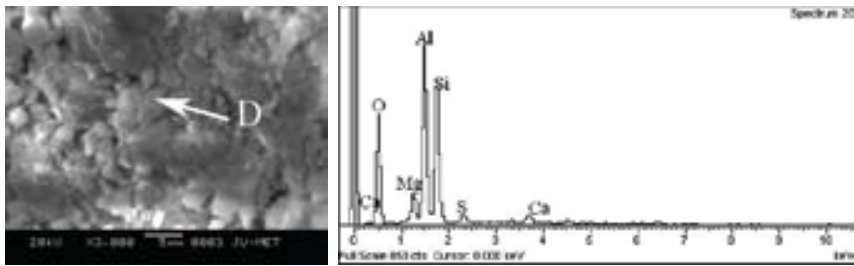

D- After 24 week exposure

Figure 7. SEM micrographs and EDX spectrum of GM2 specimen at different exposure durations.
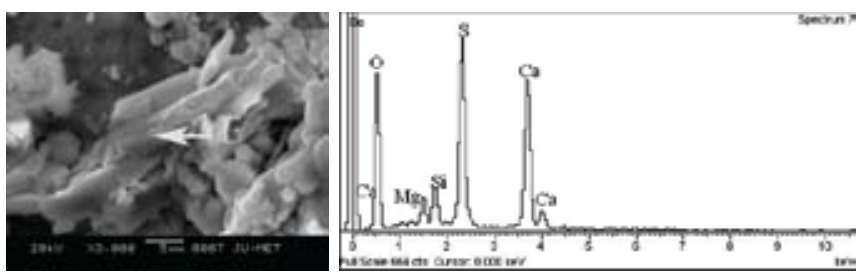

A- GM1 specimen after 12 week exposure
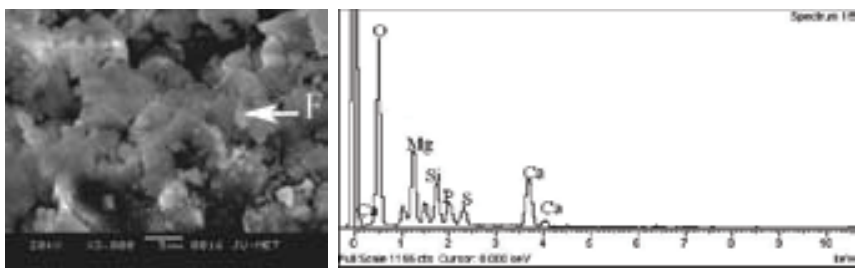

B- GM3 specimen after 12 week exposure

Figure 8. SEM micrograph and EDX spectrum of GM1 and GM3 specimen after 12 week exposure.

\section{CONCLUSIONS}

Following conclusions were drawn on the basis of the results obtained in the present study.

1. Specimens received white deposits on the surfaces during exposure to magnesium sulphate solution which gradually transformed from soft and flaky shape to hard and rounded shape.

2. No visible cracks were noticed on the specimen though fine micro cracks were seen on a few specimens through optical microscope.

3. Exposure solutions recorded considerable increase in $\mathrm{pH}$ value which can be attributed to migration of alkalis from specimen to solution. Maximum increase in $\mathrm{pH}$ occurred in solution containing specimen with highest $\mathrm{Na}_{2} \mathrm{O}$ content which suggests that more alkalis migrated from these specimens.

4. Geopolymer mortar specimen gains weight during exposure to magnesium sulphate solution and such gain are related to $\mathrm{Na}_{2} \mathrm{O}$ content of the specimen. Specimens recorded extremely low 
gain in weight; the maximum gain being noticed in the specimen with minimum $\mathrm{Na}_{2} \mathrm{O}$ content.

5. Residual compressive strength showed some fluctuations during the period of exposure. After 24 weeks of exposure, specimen with highest $\mathrm{Na}_{2} \mathrm{O}$ content retained maximum strength of
$89.7 \%$.

6. Geopolymer mortar specimen manufactured with higher alkali content performed better than those manufactured with lower alkali content.

\section{References}

1. M. D. Cohen and B. Mather, Sulfate attack on concrete-Research needs, AC1 Materials Journal, 88, (1991) 62-69.

2. M. Santhanam, M. D. Cohen, J. Olek, Sulphate attack research-whither now?, Cement and Concrete Research 31 (2001) 845-851.

3. P. K. Mehta, Mechanism of expansion associated with ettringite formation, Cement and Concrete Research 13 (1983) 401-406.

4. M. D. Cohen, Theories of expansion in sulfo-aluminate type expansive cements: Schools of thought, Cement and Concrete Research 13 (1983) 809-818.

5. I. Odler, M. Gasser, Mechanism of sulfate expansion in hydrated Portland cement, J. Am. Ceramic Society 71(11)(1988) 1015-1020.

6. D. Bonen, M. D. Cohen, Magnesium sulfate attack on Portland cement paste: II.Chemical and mineralogical analysis, Cement and Concrete Research 22 (1992) 707-718.

7. J. Davidovits, Properties of geopolymer cements, Proceedings of the first International conference on alkaline cements and concretes vol.1, SRIBM, Kiev (1994) 131-149.

8. T. Bakharev, Resistance of geopolymer materials to acid attack, Cement and Concrete Research 35 (2005) 658-670.
9. X. J. Song, M. Marosszeky, M. Brungs and R. Munn, Durability of fly ash based geopolymer concrete against sulphuric acid attack, 10 DBMC International conference on durability of building materials and components, Lyon, France (2005).

10. S. Thokchom, P. Ghosh and S. Ghosh, International Journal of Recent Trends in Engineering, 1(6) (2009) 36-40.

11. S. Thokchom, P. Ghosh and S. Ghosh, ARPN Journal of Engineering and Applied Sciences 4(1) (2009) 65-70.

12. S. E. Wallah and B. V. Rangan, Low calcium fly ash based geopolymer concrete: Long term properties, Research report GC2, Curtin University of Technology, Australia (2006).

13. T. Bakharev, Durability of geopolymer materials in sodium and magnesium sulphate solutions, Cement and Concrete Research 35 (2005) 12331246.

14. R. Thakur and S. Ghosh, Fly ash based geopolymer composites, Proceedings of $10^{\text {th }} \mathrm{NCB}$ International seminar on cement and building materials, New Delhi, India 3 (2007) 442-451.

15. F. Rendell and R. Jauberthie, The deterioration of mortar in sulphate environments, Cement and Concrete Research 13 (1999) 321-327. 